\title{
O TRABALHO COMO CATEGORIA DE ANÁLISE NA EDUCAÇÃO DO DEFICIENTE VISUAL
}

\author{
Celi Corrêa Neres* \\ NesDete Mesquita CorrêA ${ }^{* *}$
}

\begin{abstract}
RESUMO: O objetivo deste texto é discutir o trabalho como uma categoria de análise na educação do deficiente visual. Sob esse aspecto, evidencia que a compreensão das formas de trabalho, em cada momento da existência humana, revela a organização social e a própria história da humanidade. Para tanto, baseando-se no conceito de trabalho em Marx, houve a preocupação de revisitar a trajetória da educação especial, situando a organização dos modos de produção da sociedade e a educação do deficiente visual. Assinala que as alternativas para superar dificuldades de emprego e da possibilidade de inclusão social das pessoas com deficiência visual exigem investimento em sua educação, na qualidade de vida e na sua inserção no trabalho. Conclui-se que é de fundamental importância a existência de uma proposta educacional que supere a exclusão e a necessidade de transformação das atuais relaçooes de trabalho na sociedade capitalista, bem como o estabelecimento de um novo projeto político-social.
\end{abstract}

Palavras-chave: Trabalho. Sociedade. Educação. Deficiência visual.

\section{LABOR AS AN ANALYSIS CATEGORY IN THE EDUCATION OF THE VISUAL DEFICIENT}

ABSTRACT: The aim of this text is to discuss labor as an analysis category in the education of the visual deficient. In this sense, it indicates that the comprehension of the kinds of labor, in each moment

\footnotetext{
* Mestre em Educação e docente da Universidade Estadual de Mato Grosso do Sul (UEMS) e da Universidade para o Desenvolvimento da Região do Pantanal (UNIDERP). E-mail: c.neres@uol.com.br

** Mestre em Educação e docente da Universidade Estadual de Mato Grosso do Sul (UEMS) e do Centro Universitário de Campo Grande (UNAEs). E-mail: nesdete@ig.com.br
} 
of the human existence, reveals the social organization and the humanity history itself. Thus, from the concept of labor in Marx, there was a care to review the way of especial education, situating the organization of the production manners of society and the education of the visual deficient. It marks that the alternatives to overcome the labor difficulties and the possibility of social inclusion of the people with visual deficiency require investments in their education, in quality of life and their insertion in labor. It concludes that it is basically important the existence of an educational proposal that overcomes the exclusion and the necessity of transformation of the labor relation in capitalist society nowadays, as well as the establishment of a new political and social project.

Key words: Labor. Society. Education. Visual deficiency.

\section{Introdução}

$\mathcal{A}$ categoria trabalho ganha centralidade na análise da sociedade e, conseqüentemente, da educação e, em particular, neste objeto de estudo, a educação do deficiente visual, na medida em que a compreensão das formas de trabalho em cada momento da existência humana revela a organização social e a própria história da humanidade.

Marx afirma que, por meio do trabalho, o homem não só produz a sua existência como também a si mesmo e a própria história. Segundo Marx, “(...) O primeiro ato histórico é, portanto, a produção dos meios que permitem a satisfação destas necessidades, a produção da própria vida material" (Marx \& Engels, 1993, p. 39).

Lancillotti (2003), ao analisar a categoria trabalho na sociedade capitalista, afirma que essa ação humana permite ao homem, por meio da interação, transformar a natureza e a si mesmo.

O periódico Mensageiro Europeu de São Petersburgo, em um artigo intitulado "O Capital", pronuncia uma crítica da obra de Marx e afirma que para Marx “(...) cada estágio de desenvolvimento tem uma lei própria de população. Com o desenvolvimento diferente das forças produtivas, mudam as relações sociais e as leis que as regem" (Mensageiro Europeu apud Marx, 1980, p. 16).

Como base no exposto, o fio condutor da presente análise constitui-se na concepção de que cada sociedade, ao organizar suas formas de trabalho, produz ideais que sustentam e fundamentam as diferenças 
entre os homens e estabelecem, portanto, um modelo de educação que atenda às necessidades produzidas em cada momento histórico.

Considerações sobre educação, trabalho e deficiência

\section{Pontuando a história}

Ao analisar historicamente como cada sociedade se organizou em torno das relações de trabalho, pode-se desvelar as propostas educacionais desenvolvidas para a educação especial e para a pessoa com deficiência visual.

Assim, na comunidade primitiva, o atendimento às necessidades dos homens estava na dependência da própria natureza e no que esta lhes proporcionava: condiçôes básicas de sobrevivência, como caça, pesca e abrigo.

Embora o trabalho fosse realizado em comum, na procura da sobrevivência, cada indivíduo deveria ser capaz de prover seu próprio sustento e defesa, caso contrário, poderia ser abandonado. Nesse caso, aquele indivíduo com algum tipo de deficiência acabava por tornar-se um empecilho, um peso que devia ser abandonado e relegado à própria sorte, o que se pode verificar nos estudos de Guhur (1992).

O desenvolvimento das forças produtivas (descoberta do uso de metais, fabricação de instrumentos e desenvolvimento de novas técnicas de trabalho), especialmente nas atividades ligadas à criação de gado e agricultura, faz com que o produto do trabalho dos homens e o aumento da produtividade passem a exigir novas formas de realização social.

Essas mudanças permitem uma nova forma de produzir a vida e, portanto, novas formas de organização social. $\mathrm{Na}$ sociedade grega, com o atendimento às necessidades básicas garantidas pelo escravo, os homens livres podiam dedicar-se à contemplação, à política e à filosofia.

Analisando o exemplo de Esparta, verifica-se a valorização dos atributos físicos necessários à ginástica, dança e estética. Os homens livres dedicavam-se à arte de guerrear. Aqueles que não eram bem dotados fisicamente e apresentavam algum tipo de deformidade ou deficiência eram eliminados.

Já em Atenas, com o homem ligado à pólis, ${ }^{1}$ a maior virtude consistia na capacidade de governar, na boa argumentação, na filosofia e na 
contemplação. Só podiam sobreviver aqueles que se ajustassem a essas condiçôes. Assim, na sociedade antiga era comum o infanticídio e o extermínio de crianças com deficiência.

A prática do abandono, ou seja, da exposição de pessoas com deficiência foi admitida por Aristóteles em nome do equilíbrio demográfico, especialmente nos casos em que implicassem dependência econômica: "Quanto a rejeitar ou criar recém-nascidos terá de haver uma Lei, segundo a qual nenhuma criança disforme será criada, com vistas a evitar o excesso de crianças (...)" (Aristóteles, 1985, p. 267).

Como eram consideradas incapazes para sobrevivência, na sociedade primitiva as pessoas com deficiência não atendiam aos padrões sociais atribuídos aos homens, portanto eram denominados deficientes, disformes (...) (Carmo, 1991, p. 49).

$\mathrm{Na}$ Idade Média, uma nova forma de organização da produção se estabeleceu entre os homens: o feudalismo. Essa organização caracterizou-se pela propriedade feudal da terra, em torno da qual se deram as relações de produção, baseadas na agricultura e, posteriormente, no comércio. Tais relações caracterizavam-se pela servidão do trabalhador ao senhor feudal. Os princípios religiosos eram forças dominantes nesse período e a prática do abandono das pessoas com deficiência passou a ser condenada.

A introdução da doutrina religiosa e a disseminação de valores como caridade, compaixão, valorização da pobreza etc. passaram a provocar mudanças nos costumes e atitudes dos homens. As pessoas com deficiência passaram a ser donas de alma e filhas de Deus como todos os homens. É assim que passaram a ser, ao longo da Idade Média, "Les enfants du bon Dieu, numa expressão que tanto implica a tolerância e a aceitação caritativa (...)" (Pessotti, 1984, p. 5).

Com essa nova concepção, as pessoas com deficiência passaram a ser acolhidas em igrejas, onde foram organizados orfanatos, abrigos para atendê-las com as crianças pobres e desamparadas.

Ainda nessa concepção, a deficiência também poderia ser vista como resposta aos comportamentos imorais dos homens, "um justo castigo dos céus" aos pecados cometidos pelo próprio indivíduo, até então denominado cretino, ou ainda por seus semelhantes e familiares (Pessotti, 1984, p. 6). 
A pessoa com deficiência, nessa perspectiva, deveria receber dos homens tolerância e aceitação. A deficiência, fruto da vontade divina, teria como objetivo chamar a atenção dos homens para as mazelas do mundo, dando-lhes chance de reflexão e regeneração:

Outra forma, embora menos enfática, de a igreja ver e explicar a existência de cegos, mudos, paralíticos, loucos, leprosos, enfim, de pessoas portadoras de qualquer deficiência, era a de que eles eram instrumentos de Deus para alertar os homens, para agraciar as pessoas com a possibilidade de fazerem caridade (...). (Bianchetti, 1995, p. 11)

$\mathrm{O}$ atendimento à pessoa com deficiência era caracterizado pela segregação em asilos que garantiam teto e alimentação. Servia também de proteção à sociedade, na medida em que isolava aquele que incomodava (por meio das condutas indecorosas e anti-sociais).

Profundas transformaçōes no modo de produção, ainda no interior do feudalismo, trazem mudanças significativas nas relações entre os homens. $\mathrm{O}$ aumento da produção de excedentes, resultado da aplicação de novas técnicas no campo e do cultivo de maior extensão de terras, possibilitou a ampliação da troca e do comércio. Essa situação resultou na formação de centros comerciais nas cidades: os burgos que, paulatinamente, se tornaram o principal centro mercantil e de circulação de mercadorias.

O incremento técnico na agricultura, aliado a outros fatores combinados, permitiram a liberação de grande massa de trabalhadores que antes se ocupava de atividades ligadas à terra, para o exercício de outras como o artesanato e o comércio.

A produção artesanal organizou-se com normas, regulamentos de trabalho e aprendizagem, sob a forma de corporaçôes de ofício. Tal atividade tinha fins lucrativos, comerciais e atendia a uma classe em ascensão: a burguesia.

Com o gradativo predomínio de uma produção voltada ao mercado, a possibilidade de acumulação e o desenvolvimento da ciência que garanta o domínio do homem sobre a natureza foram os principais fatores de contribuição para o estabelecimento de novas relações entre os homens, inaugurando outro momento histórico. Esses passam a ser entendidos como seres naturais, centros do universo: isso significa novas formas de pensamento (religioso, político e moral) e nova forma de vida. 
Nessa linha, a ordem não é mais estabelecida pelos princípios religiosos, pelo sobrenatural: a Igreja, instituição bastante forte até então, passa a ser enfraquecida. O domínio da ciência constituiu-se no conhecimento necessário ao novo modo de produção, para possibilitar o acesso a novas técnicas e instrumentos de trabalho cada vez mais precisos e adequados. Essa nova forma já não explicava a existência humana pela manifestação divina, mas pelo pensamento racional e por princípios e leis próprias (Guhur, 1992).

As doenças mentais deixam de ser explicadas pelas interferências divinas, religiosas; passam a ter explicaçôes naturais. Com Paracelso (1493-1541) e Cardano (1501-1576), a "deficiência" deixa de ser um problema teológico e moral para ser um problema médico, digno de tratamento. Com Sir Anthony Fitz-Hebert (1534), a idiotia se define como enfermidade ou produto de infortúnios naturais; Thomas Willis (16211675) explica a natureza organicista da deficiência como resultado de lesões ou disfunções do sistema nervoso central; John Locke (16321704) inaugura a visão naturalista da atividade mental (intelectual), liberando-a das explicações estritamente morais e religiosas (Pessotti, 1984, p. 15-17).

Locke, em sua teoria da tábula rasa, postula que a mente humana funciona como uma página em branco. A experiência e o ensino deveriam suprir suas lacunas. $\mathrm{O}$ idiota é compreendido como aquele que se encontra em estado de carência de idéias e operações intelectuais semelhantes ao recém-nascido (Locke, 1978, p. 146).

A teoria do conhecimento de Locke mudou a concepção então vigente e dominante; entretanto, não garantia, ainda, o atendimento educacional à pessoa com deficiência. "Inútil para a lavoura e o artesanato, consumidor improdutivo da renda familiar, o idiota, o deficiente permanecia no abrigo, onde recebia cuidados e alimentação" (Pessotti, 1984, p. 24).

Com a condenação da ociosidade e a exaltação do trabalho, no interior da sociedade burguesa, aqueles que por alguma incapacidade não podiam produzir, como "os deficientes" (loucos ou idiotas ${ }^{2}$ ), passaram a ser rejeitados. Esses indivíduos tornam-se, com os pobres, ociosos e delinqüentes, um peso e uma ameaça. A eles era dado o destino da segregação: internação sob tutela do Estado. Necessário, nesse momento, para assegurar a produção de riquezas e sua circulação, o trabalho passa a ser uma das atividades produtivas mais importantes. 
Assim, a assistência aos pobres, crianças abandonadas e pessoas com deficiência deixa de ser tarefa só da Igreja e passa a fazer parte também do Estado, que incrementou seus próprios recursos econômicos e financeiros, por meio da arrecadação de taxas e tributos sobre as práticas produtivas e comerciais da burguesia e transferiu o resultado arrecadado para setores improdutivos da sociedade.

$\mathrm{Na}$ medida em que buscava ascensão, a burguesia pressionava o Estado para se organizar em torno de uma nova ordem que lhe possibilitasse assegurar riqueza e acumulação. Uma das formas era tornar o trabalhador, antes na condição de servo, em trabalhador livre, proprietário de si próprio: habilitado a vender sua força de trabalho por um salário, garantindo assim, sua sobrevivência. Essa condição, mais tarde, consolidará os princípios da igualdade e liberdade burguesas.

Essa relação de compra e venda de trabalho que se realizou já no interior das manufaturas, estabilizar-se-á com o emprego da maquinaria, quando grande número de trabalhadores será transformado em força de trabalho.

O trabalho no interior das manufaturas, caracterizado pelo parcelamento das tarefas do trabalhador, favoreceu um aperfeiçoamento e simplificação dos instrumentos de trabalho ajustados às ações parciais que cada um deveria realizar. Essas mudanças nos instrumentos e processos de trabalho constituíram-se em ponto inicial para o desenvolvimento da máquina (combinação de ferramentas simples e diferenciadas).

A introdução da máquina na produção e as mudanças nas relações de trabalho marcaram de maneira mais incisiva o fim do feudalismo e o estabelecimento de uma nova forma social, o capitalismo.

O trabalhador que antes, na manufatura, comandava com sua própria habilidade o ritmo e o tempo de trabalho com o emprego da máquina, fica destituído desse controle. Nessa forma de trabalho, o trabalhador deve adaptar-se ao ritmo da máquina.

O trabalho assim organizado, não só retira do trabalhador o domínio no processo de produção, como também o transforma em um acessório da maquinaria. As operações realizadas por ele passam a ser objetivadas na máquina.

O parcelamento de tarefas, iniciado nas manufaturas e consagrado com o surgimento da maquinaria, simplifica e aumenta consideravelmente 
a produtividade do trabalho e o reduz a um mecanismo progressivamente mais barato. Essa forma de trabalho dispensa a especialização e a resistência do trabalhador adulto, mobilizando mão-de-obra não qualificada.

Como exemplo, podemos observar que o uso da máquina possibilitou o emprego de mulheres e crianças na produção, cuja função se resumia em apenas vigiar e corrigir o desempenho da máquina.

A primeira preocupação do capitalista ao empregar a maquinaria foi a de utilizar o trabalho das mulheres e crianças. Assim, de poderoso meio de substituir trabalho e trabalhadores, a máquina transformou-se em meio de aumentar o número de assalariados, sem distinção de sexo e idade, sob o domínio do capital. (Marx, 1980, p. 449-450)

Pode-se dizer que a divisão do trabalho imposta pelo emprego da máquina (parcelamento e simplificação de tarefas) permitiu a incorporação de mulheres, crianças e também dos "deficientes" na produção.

Percebe-se, então, que na sociedade capitalista todo empenho deve ser feito para transformar todos os homens (deficientes ou não) em trabalhadores (homens livres capazes de vender sua força de trabalho).

São raros os registros de "deficientes ou idiotas", incorporados à produção no início do capitalismo. Porém, observam-se algumas referências feitas por Marx, em O Capital, acerca do emprego de "idiotas", ainda no interior das manufaturas: "Realmente, em meados do século XVIII, algumas manufaturas empregavam de preferência indivíduos meio idiotas em certas operações simples que constituíam segredos de fabricação" (Marx, 1980, p. 414).

Mais adiante, na mesma obra de Marx, observa-se com a utilização do trabalho de crianças, a mão-de-obra do deficiente sendo aproveitada pelos donos de fábricas “(...) Não há muitos anos, uma paróquia de Londres e um fabricante fizeram um contrato que estipulava que uma criança idiota seria incluída em cada lote de 20 sadias" (idem, ibid., p. 877). Em outra passagem de $O$ Capital, há referência ao rapto de crianças nos asilos, por parte dos donos de fábricas, para incorporação no trabalho.

(...) inclinaram-se a indicar como causa do prolongamento da jornada de trabalho nas fábricas, o monstruoso rapto de crianças praticado pelos capitalistas no início do sistema industrial moderno, em asilos e orfanatos, obtendo por esse meio, material humano desprovido de vontade. (Fielden apud Marx, 1980, p. 460) 
Como se observou anteriormente, esses asilos e orfanatos eram ocupados por crianças desamparadas, indigentes, "idiotas" e "deficientes".

Aqui, pode-se destacar que a divisão do trabalho também permitiu a incorporação dos deficientes visuais na produção. Uma pesquisa realizada por Neres (1999) mostra que ainda hoje os postos de trabalho ocupados pelos cegos são tradicionalmente aqueles em que a visão é dispensável. ${ }^{3}$

Com a divisão do trabalho, o desempenho de cada tarefa vai impor as especialidades. De cada trabalhador exigir-se-á apenas sua eficiência para aumentar a produção. $\mathrm{O}$ aumento da produtividade requer o controle dos métodos e processos de trabalho. Com Taylor e Ford, temse a contribuição científica acerca desse controle, pelo desenvolvimento de procedimentos (cadeia de métodos e organização do trabalho) que garantam a eficiência do trabalho.

Por meio dos princípios da administração científica, Taylor descreve como a produção pode ser aumentada pela decomposição de cada parte do processo de trabalho em movimentos específicos e pela organização de tarefas fragmentadas segundo padrōes rigorosos de tempo e movimento.

Com Ford, a divisão do trabalho torna-se intensa a favor da produtividade. A realização de tarefas simples e mecanizadas permite a incorporação de pessoas com deficiência na produção:

Pela época que Henry Ford começou a fabricar o modelo T, em 1908, não eram necessárias 18 operaçôes diferentes para completar uma unidade, mas 7.882. Em sua autobiografia, Ford registrou que destas 7.882 tarefas especializadas, 949 exigiam homens fortes fisicamente perfeitos; 3.338 tarefas precisavam de homens de força física apenas comum, a maioria do resto podia ser realizada por mulheres e crianças crescidas, e continuava friamente, verificamos que 670 tarefas podiam ser preenchidas por homens sem pernas, 2.637 por homens de uma perna só e 10 por homens cegos, em suma, a tarefa especializada não exigia homem inteiro, mas apenas uma parte. (Toffler, 1980, p. 62)

Kuenzer (2000) assinala que no modo taylorista/fordista de organização e gestão do trabalho, as relações entre educação e trabalho eram mediadas por modos de fazer. Assim, para o trabalhador ser considerado qualificado bastava executar suas tarefas com habilidade, o que, na maioria das vezes, era adquirida mediante "treino" e experiência na execução das tarefas. 
Desse modo, na medida em que o trabalho se torna parcelado e simplificado, a pessoa com deficiência pode ser aproveitada para o trabalho, passando a ser mais uma força de trabalho disponível ao capital. Nessa perspectiva, deve-se buscar a compreensão da educação e da educação profissional da pessoa com deficiência. A preocupação com a inserção destes no trabalho está presente nas primeiras iniciativas de "atendimento educacional" aos ditos anormais, a partir da justificativa de serem capazes de produzir.

Em Coménio (1976), ainda no século XVII, observa-se a defesa da educação dos "débeis mentais" para inserção na vida social, no trabalho e até mesmo na obediência dos princípios morais e éticos da sociedade burguesa:

(...) com efeito, quanto mais alguém é de natureza rude, tanto mais tem necessidade de ser ajudada, para que, quanto possível se liberte de sua debilidade e da sua estupidez brutal. (...) assim também os débeis e os estúpidos, mesmo que nos estudos não façam nenhum progresso, tornam-se todavia mais brandos nos costumes, de modo a saberem obedecer as autoridades políticas e os ministros da igreja (...). (Coménio, 1976, p. 140)

Segundo Pessotti (1984), um movimento foi instalado para criar estabelecimentos consagrados unicamente aos "idiotas", para tornar a idiotia menos pesada e mais suportável. Já em 1824, para manter sua economia doméstica, os asilos e hospícios procuravam instruir os idiotas e imbecis na execução de tarefas manuais ou no domínio dos processos intelectuais exigidos pela vida em sociedade.

É o nascimento da educação especial em nome da educabilidade dos "idiotas" e "deficientes", com o objetivo de torná-los úteis à sociedade, ou seja, fazê-los produtivos: "O idiota deverá ganhar seu pão com o suor de sua fronte. Como? Aprendendo os bons costumes e algum tipo de trabalho no estabelecimento especial chamado asilo-escola" (Pessotti, 1980, p. 164).

$\mathrm{O}$ asilo-escola abrigava deficientes, surdos, cegos e "deficientes mentais" que, em troca de moradia e alimentação, deveriam exercer trabalho obrigatório. Um exemplo desse tipo de atendimento, até então denominados surdos, cegos, loucos foi a abertura do Instituto para Cegos de Nascimento, em Paris (1791), que somente aceitava cegos capazes de trabalhar. Em 1795, esse estabelecimento recebeu o nome de Instituto dos Trabalhadores Cegos, transformando-se em escola industrial e asilo combinados (Bueno, 1993, p. 68-69). 
A escola de surdos fundada em 1760, em Paris, caracterizada como internato, também se preocupava com a liberação do surdo para o trabalho. Os deficientes mentais seguem o mesmo exemplo. Embora atendidos em hospícios ou "escolas ligadas" aos hospitais, aqueles que apresentavam mínimas condições eram levados a responder às exigências do processo produtivo. (Bueno, 1993).

Esse tipo de atendimento "educacional" teve início na França, onde o desenvolvimento industrial e a consolidação do Estado burguês exigiam novas formas de tratar o "deficiente": prepará-lo e aproveitá-lo para o trabalho. Tal preparação consistia apenas em aprendizado de alguma linguagem gestual, no caso dos surdos, ou a identificação de alguma escrita em relevo com referência aos cegos. A outra grande parte do período escolar era preenchida com o trabalho manual. No caso dos surdos pode-se perceber que: "Embora grande parte desse contingente permanecesse no fim da fileira do exército de trabalhadores, sua incorporação ao trabalho passou a exigir, cada vez mais, alguma compreensão da linguagem oral" (idem, ibid., p. 69).

Essa forma de atendimento educacional especial cresceu, expandindo-se na maioria dos países capitalistas centrais; deu origem a outros tipos de estabelecimentos com diversas características: regime de internato, semi-internato e agregado às escolas de ensino-comum (aquele destinado à clientela dita normal), visto que "A expansão da educação especial iniciada no século passado foi assumindo, no decorrer do século XX, proporções cada vez maiores que se encaminham no sentido de sua institucionalização, dentro do sistema educacional, na maioria dos países ocidentais" (idem, ibid., p. 71).

Nessa sociedade, o deficiente, que antes recebia somente abrigo e alimentação, passa a receber atendimento educacional, já que em tese pode ser aproveitado para o trabalho, sendo capaz de contribuir para sua própria sobrevivência. Assim, não pôde mais ser considerado incapaz, deficiente, excepcional, ${ }^{4}$ mas sim pessoa com necessidades especiais. ${ }^{5}$

O uso do termo "pessoa com necessidades educacionais especiais" expressa a condição de que, nessa sociedade, os homens devem ser livres e capazes de exercer sua capacidade para o trabalho. Tal condição livra o deficiente, pelo menos no plano teórico, de toda expressão pejorativa de inútil ou improdutivo. Sob esse aspecto, imputa ao sujeito apenas algumas necessidades que não o impedem de participar do mundo do trabalho. 
O potencial para o trabalho e para desenvolver atitudes independentes justifica teoricamente o uso da terminologia: "pessoa com necessidades especiais". A mudança nos termos, usada nos textos oficiais e na literatura da educação especial, expressa apenas uma tentativa para dar um novo aspecto formal, de tornar o deficiente "normal", livrando-o do termo pejorativo "deficiente". $\mathrm{Na}$ verdade, segundo esses autores, a mudança de denominação muito pouco tem contribuído para mudar a forma de a sociedade tratar o deficiente.

\section{Deficiência visual: educação e mudanças no mundo do trabalho}

Atualmente, se, por um lado, tem-se o discurso a favor da educação e profissionalização da pessoa com deficiência como decorrência de seu aproveitamento para o trabalho, por outro, vivemos um momento de mudanças nesse campo, em que um grande número de trabalhadores não tem o seu emprego garantido em um mercado de trabalho bastante restrito.

Na sociedade capitalista, a incorporação da ciência e tecnologia, que possibilitou o aumento da produção em níveis cada vez maiores, trouxe consigo a automação dos processos produtivos e, como conseqüência, inúmeros trabalhadores foram expulsos da produção. $\mathrm{O}$ fenômeno da objetivação e simplificação do trabalho, intensificado com o emprego da máquina na indústria, que no passado utilizou-se do trabalho de "crianças e idiotas", com o crescente processo de automação, passou a expulsá-los da produção, sofrendo o mesmo dano um grande número de trabalhadores. Para citar apenas um exemplo, recorre-se a Gorz (1987, p. 159):

O estudo mais detalhado sobre a automatização dos empregos de escritório foi redigido, em novembro de 1976, pelo grupo Siemens. Sob o título "Projeto Escritório 1990", avalia o impacto que a mini-informática poderá ter, de agora até 1990, sobre os empregos de escritórios nas grandes casas de comércio, nas administraçōes públicas, nas grandes, médias e pequenas empresas e nas profissões liberais. Conclusão Siemens: 25 a $30 \%$ dos serviços de escritório poderão ser automatizados. Dois milhões de datilógrafos alemães, por exemplo, que batem, a cada ano, 4,4 bilhões de páginas, $40 \%$ tornar-se-ão supérfluos graças às maquinas de escrever automáticas que a Siemens constrói anualmente. Disso resultará uma economia de $32 \%$. 
Esse processo cria uma grande massa de desempregados, sem condiçôes de vender sua força de trabalho por um salário que lhe garanta sobrevivência. Tal situação dificulta o ingresso no mercado de trabalho, inclusive para a pessoa com deficiência, o que torna difícil o exercício do "direito" de ser uma pessoa produtiva, de ser auto-suficiente, de poder ser um trabalhador.

As profundas alterações no mundo do trabalho, trazidas pelo emprego de novas tecnologias, não só simplificam o trabalho, mas também diminuem o contingente de trabalhadores necessários à produção, gerando alternativas de trabalho precário, parcial, terceirizados, ligados à economia informal, conforme aponta Antunes (1995, p. 53).

A periferia da força de trabalho compreende dois subgrupos diferenciados: o primeiro consiste "em empregados em tempo integral com habilidades facilmente disponíveis no mercado de trabalho, como pessoal do setor financeiro, secretárias, pessoal de áreas de trabalho rotineiro, e de trabalho manual menor especializado". Esse grupo tende a se caracterizar por uma alta rotatividade de trabalho. O segundo grupo situado na periferia "oferece uma flexibilidade numérica ainda maior e inclui empregados em tempo parcial, empregados casuais, pessoal com contrato por tempo determinado, temporários, subcontratação e treinados com subsídios públicos, tendo ainda menos segurança no emprego do que o primeiro grupo periférico (...).

Ao tratar da globalização e crise do emprego, Frigotto (2005) afirma que nos últimos tempos "O pior cenário é o de uma radicalização das políticas neoliberais numa crescente mercantilização dos direitos sociais, a ruptura crescente da proteção ao trabalho e a instalação de um mercado auto-regulado". O autor ressalta, ainda, que nesse cenário o número de trabalhadores sobrantes, ou seja, não absorvidos pelo mercado, amplia-se, suas vidas se precarizam e ficam na dependência de planos emergenciais de alívio à pobreza, da filantropia e da caridade social.

Frigotto indica ainda que nos anos 1990, visando atender ao ideário da globalização, em nosso país, efetivou-se uma alteração significativa do sistema educacional, especialmente da formação técnico-profissional. Conforme o autor, essa alteração deu-se tanto no plano organizativo quanto no político-pedagógico, cujas conseqüências somente podem ser entendidas quando situadas no contexto das forças econômicas e políticas. 
Para Frigotto, tal perspectiva se difere da perspectiva ideológica da teoria do capital humano dos anos 1960 e 1970, pois não tem como objetivo integrar a todos, mas somente aqueles "que adquirirem 'habilidades básicas' que geram 'competências' reconhecidas pelo mercado. Competências e habilidades para garantir não mais o posto de trabalho e ascensão numa determinada carreira, mas da empregabilidade" Frigotto (2005). Desse modo, como solucionar a questão da pessoa com deficiência visual diante das suas limitações sensoriais? Que instrumentos lhe são proporcionados para o acesso à sua profissionalização?

Kuenzer (2000, p. 135), ao abordar sobre as formas de relação entre o homem e conhecimento decorrentes das mudanças no mundo do trabalho, afirma que

Um dos principais impactos das mudanças ocorridas no mundo do trabalho sobre a educação é, sem dúvida, o estabelecimento de uma nova mediação entre homem e trabalho, que passa a ser exercida pelo conhecimento, compreendido enquanto produto e processo da práxis humana, síntese entre pensamento e ação, conteúdo e método, individual e coletivo.

Segundo a autora, diante dessa realidade, é necessária uma nova compreensão das relações entre educação e trabalho no que diz respeito à formação humana, que são absorvidas pelos Estados nacionais por meio das políticas públicas, nesse estudo compreendidas como "o 'Estado em ação', ou seja, quando o Estado implanta projeto de governo, por intermédio de programas, de ações voltadas para setores específicos da sociedade (...)" Höfling (2001, p. 31).

Kuenzer (2000) explicita ainda que, no caso da realidade brasileira, as políticas públicas incorporam as desigualdades como algo natural, as quais se articulam à lógica do mercado no processo de acumulação flexível do capital, reforçando a exclusão. Nesse contexto, isso indica que a nova relação estabelecida entre trabalho e educação é mediada por outro tipo de linguagem, a de base tecnológica, que ultrapassa o saber tido como implícito ao homem, apontando para novas exigências, inclusive no que se refere ao papel da educação.

A autora (op. cit, p. 136) discorre que, diante da progressiva perda de conteúdo do trabalho, isto é, à medida que o trabalho vai se tornando cada vez mais abstrato pela crescente incorporação de ciência e 
tecnologia ao processo produtivo para atender aos objetivos da acumulação do capital, a exigência de habilidades cognitivas, até então restritas a um pequeno número de funções, passa a ser condição para o conjunto de funções na produção, solicitando um aporte mais ampliado de conhecimento e habilidades para que o sujeito possa participar da vida social e produtiva.

Nessa perspectiva, se o trabalhador de modo geral enfrenta a exclusão determinada pelas relações estabelecidas pelo capital, a pessoa com deficiência visual enfrenta de forma mais acentuada as dificuldades para sua inserção no mercado de trabalho, haja vista que não tem as mesmas oportunidades que os outros indivíduos têm em relação à sua formação intelectual e profissional, não preenchem os padrões de 'beleza' comumente aceitos e valorizados, reforçando a descrença em relação à sua capacidade.

A pesquisa realizada por Neres (1999) revela essa situação no trabalho da pessoa com deficiência visual, ao observar que várias ocupaçóes e benefícios estão no setor informal, como venda de bilhetes, estágio remunerado e bolsa-auxílio aos programas de educação profissional.

A autora demonstra, ainda, em seu estudo, a inadequação dos programas de educação profissional que, em sua maioria, desenvolvem atividades não condizentes com a realidade do mercado de trabalho, com finalidades ocupacionais e terapêuticas. Verificou-se que há uma preocupação com a inserção no mercado de trabalho por parte dos dirigentes dos programas perante a falta de vagas.

Com o mercado de trabalho restrito, as exigências para se conseguir emprego são enormes. Diante disso, muitos empregadores usam critérios que podem ser considerados acima dos exigidos para os cargos; a escolaridade e a capacidade de flexibilização de funções são muito valorizadas.

$\mathrm{Na}$ pesquisa realizada por Neres (1999), um empregador deixa claro em entrevista que só contrata pessoa com deficiência pela comprovada produtividade. Outro fator que atrai o empregador é a contenção de despesas com o contrato de trabalho. O estudo revela, ainda, que a grande maioria dos contratos era feita em forma de estágio supervisionado. Outro fator levantado que contribui para a contratação da pessoa com deficiência é o ganho social que a instituição pode ter em sua imagem de empresa cidadã. 
Corrêa (2005), ao tratar do tema em questão, assinala que com referência às possibilidades de o deficiente visual ingressar no mercado de trabalho, de maneira geral, observa-se que, por não compreenderem que a limitação visual é comparável a qualquer outra que uma pessoa sem deficiência possa ter, os empregadores recusam-se a admitir uma pessoa com deficiência visual. Em muitas situações, ainda, as oportunidades de obtenção de emprego são obstruídas por restrições impostas pela própria legislação sobre o trabalho, ou por exigências irrealistas para a admissão em emprego, refletidas nos critérios estabelecidos pelas empresas.

Um empregador só admite um cego se for comprovada a sua competência para desempenhar determinada função e constatada sua produtividade. Sendo admitido, ele passará a ser observado. "Este cego poderá ter uma série enorme de qualidades e de bons hábitos de trabalho, no entanto, um só mau hábito, um só traço duvidoso de sua personalidade poderá ser a causa de seu afastamento". (Rocha, 1987, p. 261)

A autora indica que a pesquisa intitulada "Estudo profissiográfico, o encaminhamento do deficiente visual ao mercado de trabalho", 6 realizada por profissionais do Instituto Benjamin Constant e publicada em sua revista especializada, ${ }^{7}$ faz o levantamento de um conjunto de diversas profissões que podem ser exercidas pelas pessoas cegas e de baixa visão (visão subnormal), especificando os pré-requisitos necessários e as atribuições dessas profissões, visando auxiliar no encaminhamento profissional do deficiente visual ao mercado de trabalho.

A pesquisa faz referência aos atuais recursos ópticos e técnicos que podem ser utilizados para facilitar o desempenho funcional do deficiente visual. Obedece a objetivos específicos e princípios metodológicos, também apresenta sugestôes e recomendações para viabilização das propostas encaminhadas no estudo.

Para a realização desse estudo, foram analisadas cerca de 440 profissões de diversos níveis de escolaridade e qualificações profissionais. Apresenta como resultado a indicação de 95 ocupações compatíveis com o desempenho das pessoas deficientes visuais, os pré-requisitos, a condição visual para a sua execução e a síntese das atribuições de cada ocupação. A pesquisa também levanta as diversas profissões autônomas nas áreas rural, artesanal, industrial, comercial e de produtos caseiros. Indica cursos complementares que habilitam ao exercício profissional e à abertura do próprio negócio. 
Corrêa (2005) afirma que, na análise das profissões, foram considerados como elemento facilitador no desempenho de funções compatíveis com a deficiência visual os atuais recursos ópticos, técnicos e ambientais disponíveis no mercado, em virtude do desenvolvimento da ciência e da tecnologia.

O resultado dessa pesquisa objetivou oferecer, aos serviços que atuam na área da deficiência visual, um instrumento para diminuir as dificuldades encontradas em relação à preparação e encaminhamento profissional das pessoas deficientes visuais, bem como esclarecer e orientar os empregadores quanto à capacidade produtiva desses sujeitos. A referida pesquisa indica, ainda, que o deficiente visual é uma pessoa como as demais, com preferências, habilidades, dificuldades, interesses e capacidade produtiva e que necessita apenas de oportunidade para desenvolver suas potencialidades.

De acordo com o estudo realizado no Brasil, na área comercial, industrial ou rural, existem profissões compatíveis com o desempenho do deficiente visual nos diversos níveis de formação, podendo exercê-las na condição de empregado, profissional autônomo ou empresário.

Esses dados reforçam a tese de que as possibilidades de ocupaçōes são muitas na sociedade brasileira, proporcionadas pela divisão intensa do trabalho e pelo emprego da tecnologia; este, entretanto, somado à acirrada exploração do trabalho, faz com que os postos e as oportunidades de trabalho estejam, como já evidenciado, cada vez mais restritos.

Essa realidade é preocupante, pois em nossa sociedade o trabalho é condição fundamental para a inclusão social. Verifica-se que a valorização da capacidade produtiva está presente desde as primeiras iniciativas de educação da pessoa com deficiência visual no Brasil.

Pode-se observar que já por ocasião da fundação do Instituto Imperial dos Meninos Cegos, em 1824, havia ênfase na preparação para o trabalho com o oferecimento de oficinas para aprendizagem de ofícios, como as oficinas de tipografia e encadernação para meninos cegos e de tricô para as meninas.

Jannuzzi (1990) também assinala que as políticas sociais de atendimento à pessoa com deficiência são criadas na medida em que na sociedade são considerados capazes de integrar a força de trabalho, de forma direta ou indireta, ou seja, pela liberação daqueles que se ocupam em assisti-los. 


\section{Apontamentos finais}

Diante do exposto neste estudo, podemos indagar acerca da relação entre educação, trabalho e deficiência visual e sobre quais as alternativas para superação das dificuldades de emprego e da possibilidade de inclusão social das pessoas com deficiência visual no mundo do trabalho produtivo.

Como afirma Kuenzer (2000, p. 137), embora haja diminuição dos postos de trabalho de forma acentuada como conseqüência da acumulação flexível, as mudanças ocorridas no mundo do trabalho vão exigir cada vez mais nova relação com o conhecimento para que o homem possa viver em sociedade, o que para a grande massa da população só pode ocorrer por intermédio da escola.

Desse modo, para entender os impactos ocasionados pelas mudanças no mundo do trabalho sobre a educação das pessoas, dentre elas as pessoas com deficiência visual, é preciso ter clareza de que esses impactos não ocorrem de forma linear, porém dialeticamente, pois na contradição do capital, a exclusão se expressa em investimento por parte do poder público em políticas de inclusão, entre elas a educação, contemplando no seu bojo as pessoas com deficiência.

Nessa perspectiva, Caiado (2006, p. 40), em seus estudos, ao refletir sobre as práticas pedagógicas para a educação das pessoas com deficiência visual, enfatiza que

(...) a luta contra as limitações da cegueira e suas conseqüências, compreendida numa abordagem social e histórica, revela a necessidade de se empreenderem ações em três dimensões: a prevenção da cegueira, enquanto produção social, dadas as péssimas condiçōes de vida das camadas populares; ações educacionais que coloquem fim ao isolamento da pessoa cega e ao limite entre a escola especial e a escola regular; ao acesso ao trabalho criador em contraposição ao trabalho explorado, humilhante, assistencial. (Caiado, 2006, p. 40)

A materialização das açôes propostas acima, de superação das péssimas condições de vida e saúde da população, de uma proposta educacional no sentido amplo, que supere a exclusão, parece repousar na necessidade de transformação das atuais relações de trabalho na sociedade capitalista, que significa o pensar em um novo projeto político-social. 
Para Mészáros (2005), essa transformação somente poderá ser efetivada por meio de uma proposta social, ampla e libertadora, na qual a educação em seu sentido amplo esteja "articulada adequadamente e redefinida constantemente no seu inter-relacionamento dialético com as condiçôes cambiantes e as necessidades da transformação social emancipadora e progressiva em curso" (Mészáros, 2005, p. 76-77).

Portanto, o desafio que se impõe a nós, educadores, é o de buscar caminhos que apontem para novos rumos educacionais em direção a uma proposta educativa que contemple a todos, inclusive as pessoas com deficiência visual.

\section{Recebido em março de 2008 e aprovado em julho de 2008.}

\section{Notas}

1. Pólis: Corresponde à cidade que, de certo modo, engloba o Estado completo, quer seja ela grande ou pequena em termos de território circundante ou dependente dela (Aristóteles, 1985, p. 267).

2. Segundo Jannuzzi (1985), o conceito de anormalidade de inteligência incluía indivíduos que tinham afecção mental, ou seja, os que, de certa forma, eram considerados loucos.

3. Em sua pesquisa, Neres (1999) descreveu, em relato de entrevista, que a função que mais emprega cegos em Campo Grande (MS) consiste em técnico de Câmara Escura em hospitais da região, além do emprego na própria instituição especializada.

4. Excepcional: termo utilizado para designar crianças deficientes (mental, visual, auditivo e físico), distúrbios de linguagem e problemas de conduta. Foi utilizado inicialmente nos Estados Unidos no período pós-guerra e introduzido no Brasil na década de 1970 (Bueno, 1993, p. 31-37).

5. De acordo com as Diretrizes Curriculares para a Educação Especial na Educação Básica, os alunos atendidos pela educação especial são: 1) Educandos que apresentam dificuldades acentuadas de aprendizagem ou limitações no processo de desenvolvimento que dificultem o acompanhamento das atividades curriculares, compreendidas em dois grupos: 1.1) aquelas não vinculadas a uma causa orgânica específica; 1.2) aquelas relacionadas a condições, disfunções, limitações ou deficiências; 2. Dificuldades de comunicação e sinalização diferenciadas dos demais alunos, particularmente alunos que apresentam surdez, cegueira, surdo-cegueira ou distúrbios acentuados de linguagem $(\ldots)$.

6. Pesquisa publicada na Revista do Instituto Benjamin Constant. n. 4, set. 1996) e republicada no n. 15 (abr. 2000).

7. A Revista Benjamin Constant é uma publicação técnico-científica do Centro de Pesquisa, Documentação e Informação do IBC/MEC. Destina-se à publicação de trabalhos originais, resenhas e traduçôes relacionadas às questôes de interesse das pessoas com deficiência visual.

Cad. Cedes, Campinas, vol. 28, n. 75, p. 149-170, maio/ago. 2008 


\section{Referências}

ALVES, G.L. A produção da escola pública contemporânea. Campinas: Autores Associados, 2002.

ANTUNES, R. Adeus ao trabalho? Ensaios sobre as metamorfoses e a centralidade do mundo do trabalho. 3. ed. São Paulo: Cortez, 1995.

ARISTÓTELES. Política. Brasília, DF: UNB, 1985.

BIANCHETTI, L. Aspectos históricos da educação. Revista Brasileira de Educação Especial, Rio de Janeiro, v. 2, n. 3, p. 11, 1995.

BRASIL. Ministério da Educação. Diretrizes Nacionais para a Educação Especial na Educação Básica. Brasília, DF: MEC/SEESP, 2001.

BRAVERMAN, H. Trabalho e capital monopolista: a degradação do trabalho no século Xx. Rio de Janeiro: Zahar, 1977.

BUENO, J.G.S. Educação especial brasileira: integração/segregação do aluno diferente. São Paulo: EDUC, 1993.

CAIADO, K.R.M. Aluno deficiente visual na escola - lembranças e depoimentos. 2. ed. Campinas: Autores Associados, 2006.

CARMO, A.A. Deficiência fisica: a sociedade brasileira cria, "recupera" e discrimina. 2. ed. Brasília, DF: MEC, 1991.

COMÉNIO, J.A. Didáctica magna: tratado de ensinar tudo a todos. 2. ed. Trad. de Joaquim Ferreira Gomes. Lisboa: Fundação Calouste Gulbenkian, 1976.

CORRÊA, N.M. Exclusão social e subjetividade: um estudo sobre a relação deficiência visual e trabalho no contexto da globalização. In: IV Congresso Internacional de Educação, 2005, São Leopoldo (RS). A educação nas fronteiras do humano. São Leopoldo: UNISINOS, 2005. p. $1-15$. v. 1.

FILGUEIRAS, C.A. C. Trabalho, sociedade e políticas sociais. Cadernos de Pesquisa, São Paulo, n. 97, p. 13-20, 1996.

FRIGOTTO, G. Globalização e crise do emprego: mistificações e perspectivas da formação técnico-profissional. Disponível em: <http:// 
www.senac.br/informativo/BTS/252/boltec252c.htm>. Acesso em: 29 dez. 2005

GORZ, A. Adeus ao Proletariado - para além do socialismo. Rio de Janeiro: Forense Universitária. 1987.

GUHUR, M.L.P. Representação da deficiência mental: esboço de uma abordagem histórica. 1992. Dissertação (Mestrado em Educação) Universidade Metodista de Piracicaba, Piracicaba.

HÖFLING, E. Estado e políticas (públicas) sociais. Cadernos CEDES, Campinas, n. 55, p. 30-41, 2001.

JANNUZZI, G.M. A luta pela educação do deficiente mental no Brasil. São Paulo: Cortez, 1985.

JANNUZZI, G.M. Políticas sociais públicas de educação especial. Revista Vivência, São José (sC), n. 12, p. 24-25, 1990.

KUENZER, A.Z. Educação, linguagens e tecnologias: as mudanças no mundo do trabalho e as relaçóes entre conhecimento e método. In: Cultura, linguagens e subjetividade no ensinar e aprender. Encontro Nacional de Didática e Prática de Ensino (ENDIPE). Rio de Janeiro: DP\&A, 2000.

LANCILLOTTI, S.S.P. Deficiência e trabalho. Campinas: Autores Associados, 2003.

LOCKE, J. Ensaio acerca do entendimento humano. 2. ed. São Paulo: Abril Cultural, 1978.

MARX, K. ; ENGELS, F. A ideologia alemã. 9. ed. São Paulo: Hucitec, 1993.

MARX, K. O Capital. Crítica da economia política. 4. ed. Rio de Janeiro: Civilização Brasileira, 1980. L.1, v. 2.

MÉSZÁROS, I. A educação para além do capital. São Paulo: Boitempo, 2005.

NERES, C.C. Educação profissional do portador de necessidades especiais para quê? (O caso de Campo Grande - MS). 1999. 208p. Dissertação (Mestrado em Educação) - Universidade Federal de Mato Grosso do Sul, Campo Grande. 
PESSOTTI, I. Deficiência mental: da superstição à ciência. São Paulo: USP, 1984. p. 5.

REVISTA BENJAMIN CONSTANT. Rio de Janeiro, n. 4, 1996.

ROCHA, H. et al. Ensaio sobre a problemática da cegueira. Belo Horizonte: Editora da Fundação Hilton Rocha, 1987.

SFORNI, M.S.F. A feminização do corpo docente na democratização do ensino do século XIX. 1996. Dissertação (Mestrado em Educação) Universidade Estadual de Maringá, Maringá.

TOFFLER, A. A terceira onda. 5. ed. Rio de Janeiro: Record, 1980. 